\title{
Cheiro-oral syndrome with bilateral oral involvement: a study of pontine lesions by high-resolution magnetic resonance imaging
}

\author{
SADAYUKI MATSUMOTO,* SHIZUMA KAKU,* MASAHIRO YAMASAKI,* \\ TERUKUNI IMAI, * HIDEHIKO NABATAME, $\dagger$ MASAKUNI KAMEYAMA $\ddagger$ \\ From the Department of Neurology, Kitano Hospital and Neurological Center, ${ }^{*}$ Tazuke-Kohukai Medical \\ Institute, Osaka, Department of Neurology, Faculty of Medicine, $\dagger$ Kyoto University, Kyoto, Sumitomo \\ Hospital, Osaka, Japan
}

SUMMARY Two cases of unusual cheiro-oral syndrome due to small pontine haemorrhage are described, in which both sides of the mouth were involved in the initial stage. High resolution magnetic resonance imaging revealed a small lesion at the paramedian pontine tegmentum in both cases and suggested involvement of the medial portion of the medial lemniscus.

In 1914 Sitting $^{1}$ first described a sensory defect observed around the corner of the mouth and on the palm on the same side of the body, the cheiro-oral syndrome. The syndrome is usually considered to be due to a small lesion in the contralateral post-central gyrus of the parietal lobe ${ }^{1}$ or to a lesion in the thalamus ${ }^{2-4}$ limited to the inferior medial portion of the ventral posterolateral nucleus and the lateral part of the ventral posteromedial nucleus of the thalamus. ${ }^{3}$ Recently, some cases of this syndrome associated with brainstem lesions have been reported. ${ }^{5-9}$ We report two cases of small pontine haemorrhages showing an unusual cheiro-oral syndrome, in which both sides of the mouth were involved. Magnetic resonance imaging (MRI) revealed details of the lesion in the pontine tegmentum in both cases.

\section{Case reports}

Case 1 A hypertensive 38 year old man suddenly felt dizzy followed by numbness in his lower right face and his right hand and was admitted to hospital on the same day. He remained alert and was not dysarthric. Dysaesthesia and mild sensory defects of pain, temperature and tactile sensations

Address for reprint requests: Dr Sadayuki Matsumoto, Bluestone Laboratory of the Division of Neuropathology, Montefiore Medical Center, 111 East 210th Street, Bronx, New York 10467, USA.

Received 30 September 1988 and in revised form 30 December 1988 Accepted 10 January 1989 were found all around his mouth, on the oral mucosa and of his right palm. There was no sign of either weakness of cerebellar ataxia. Sensory defects of both sides of the mout persisted only for three days, after which the left side of the mouth was affected. In a month all sensory defects hag $\bar{\nabla}$ disappeared.

CT detected a small haematoma in the left paramediaf tegmentum of the upper pons and the midbrain, and an old small infarct in the left putamen. MRI using a 1.5-T superconducting unit (Sigma System, General Electric, Milwaukee) demonstrated the small lesion precisely and the sagittal image delineated the rostro-caudal extension (fig 1). Case 2 A hypertensive 47 year old woman on renal dialysis suddenly felt headache, nausea and numbness around her mouth and right fingers. On admission, she was alert but slightly dysarthric. Her pupils were slightly anisocoric but promptly reactive. Dysaesthesia around both sides of her mouth and on her right fingers persisted, but no objective hypaesthesia was detected. Right hemiparesis and bilateral cerebellar ataxia were noted, and the Babinski sign was present on the right side. On the ninth hospital day, numbness around the mouth remained only on the right side and disappeared completely in a month.

CT revealed a haematoma in the left paramedian region of the mid-pons. MRI disclosed in more detail two small lesions involving the paramedian pontine tegmentum and the dorsal basis pontis (fig 2). No other lesions were found in the thalamus and parietal lobe.

\section{Discussion}

The cheiro-oral syndrome has so far been reported associated with small lesions of the parietal post- 

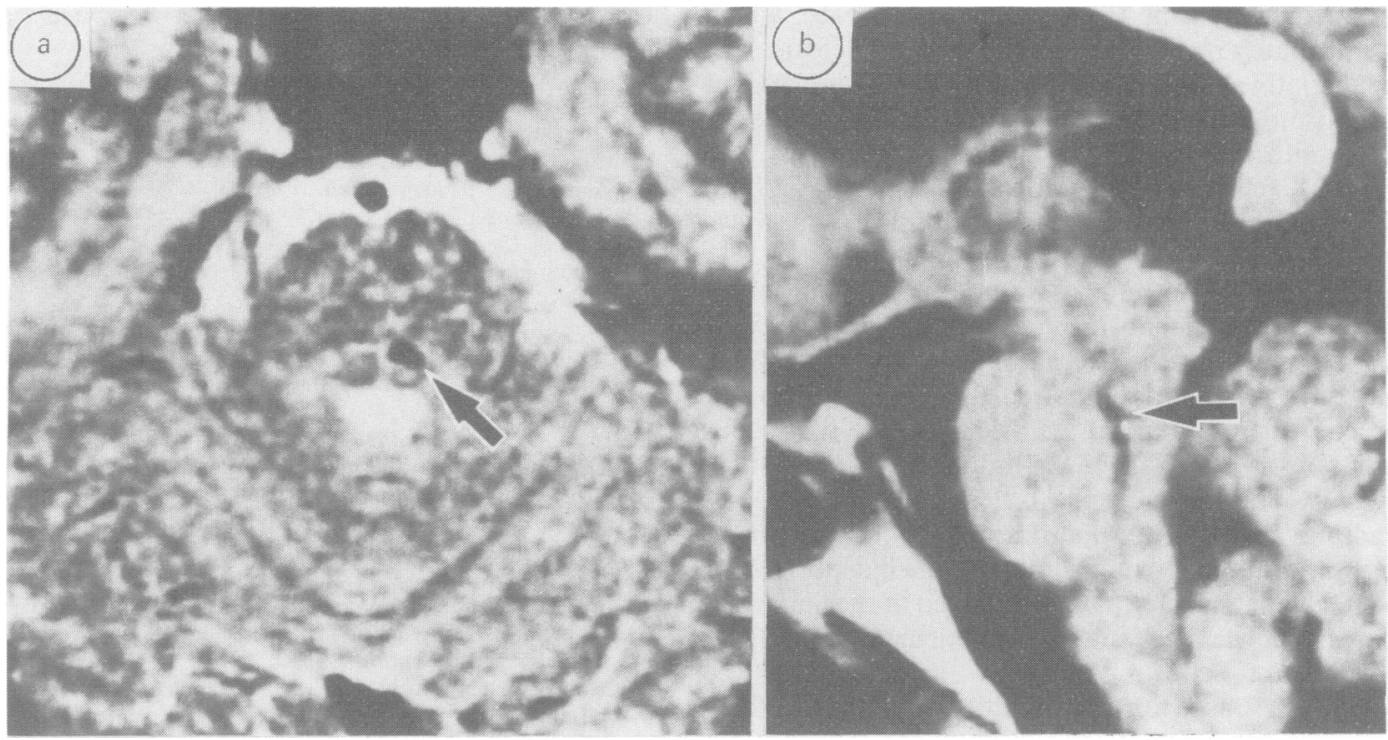

Fig 1 (Case 1) (a) Axial T2-weighted image. (spin echo, TR: $2000 \mathrm{~ms}, \mathrm{TE}: 80 \mathrm{~ms}$ ). A small low-intensity area is located at the paramedian tegmentum of the upper pons (arrow). (b) Sagittal Tl-weighted image. (partial saturation recovery. TR: $400 \mathrm{~ms}, T E: 25 \mathrm{~ms}$ ) A slit-like low intensity area is located at the tegmentum in the middle to upper pons (arrow).

central gyrus, ${ }^{1}$ thalamus, ${ }^{L-4}$ and, recently, in the brainstem tegmentum. ${ }^{5-9}$ The combined unilateral sensory disturbance of the hand and the corner of the mouth is thought to be derived from the close somatotopical localisation of the thalamic sensory nuclei and the

sensory cortex of the parietal post-central gyrus.

In the brainstem lesions, clinical and CT findings suggest that the syndrome is due to partial involvement of the medial lemniscus. ${ }^{7-9}$ In our cases, MRI studies clearly delineated a small lesion at the
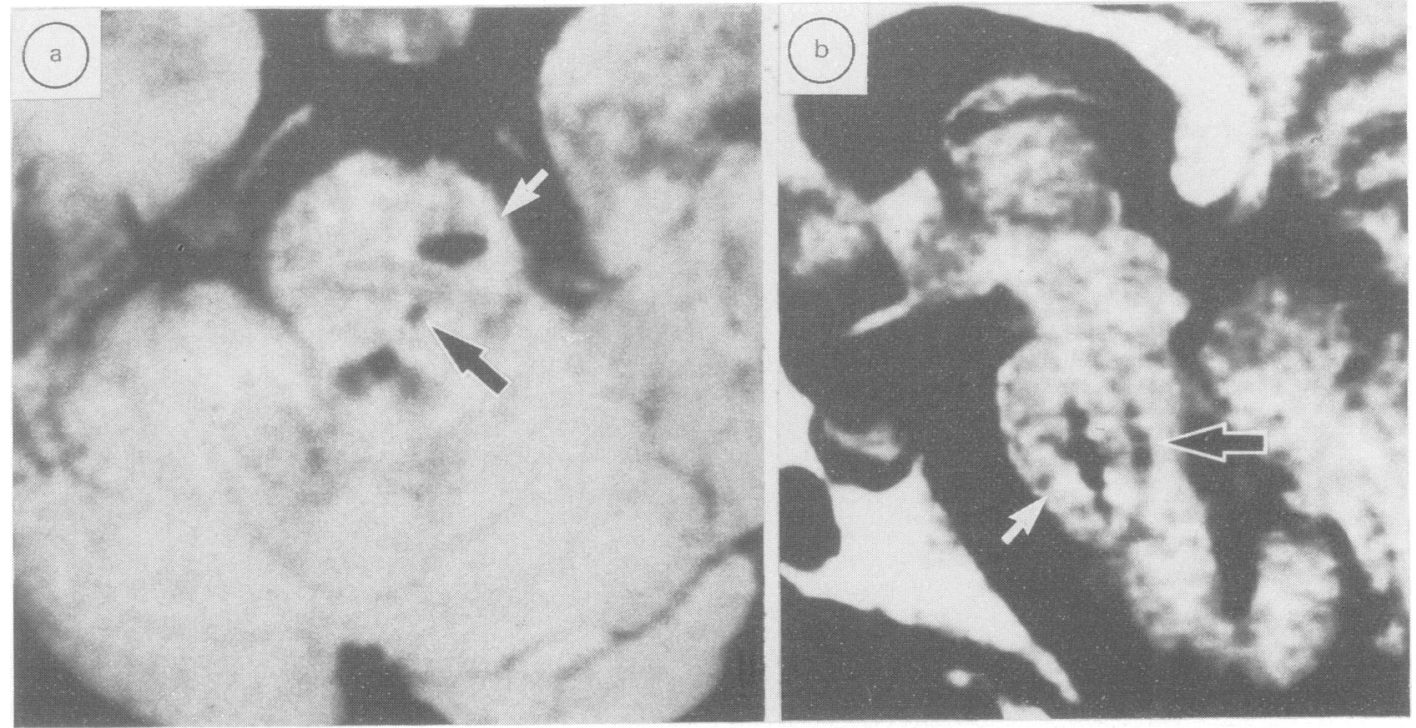

Fig 2 (Case 2) (a) Axial T2-weighted image. (spin echo, TR: $2000 \mathrm{~ms}, \mathrm{TE}: 40 \mathrm{~ms}$ ) Two low-intensity areas are located at the basis of the pons (white arrow) and at the paramedian pontine tegmentum (black arrow). (b) Sagittal T1-weighted image (partial saturation recovery. TR: $400 \mathrm{~ms}, T E: 25 \mathrm{~ms}$ ) Two slit-like low intensity areas are noted at the base (white arrow) and tegmentum (black arrow) of the middle pons. 
paramedian pontine tegmentum in each case, which was probably responsible for the sensory defects. The basal pontine lesion in case 2 was probably the cause of paresis and ataxia. It is noteworthy that both sides of the mouth were involved at the initial stages. No previous cheiro-oral syndrome case has been associated with such a sensory distribution as far as we are aware.

The clinico-anatomical basis for the temporary bilateral involvement of the mouth is unknown. One possibility is that the haematomas in the acute stage may have transiently impaired the medial portion of the contralateral medial lemniscus, where the secondary sensory fibres from the mouth are located most medially and close to the other side. ${ }^{10}$ The second possibility is that the uncrossed fibres of the dorsal trigeminothalamic tract ${ }^{10}$ and the medial portion of the medial lemniscus may be involved in the unilateral brainstem. The mechanism of impairment of pain and temperature sensation in case 1 remains to be elucidated. Based on these clinico-radiological findings, the present cases show at least that a brainstem lesion can produce a sensory defect involving both sides of the mouth in a cheiro-oral syndrome.

We thank Drs Asao Hirano, Hidehiro Mizusawa and
Herbert $M$ Dembitzer for their advice and encouragement in preparing this manuscript.

\section{References}

1 Sitting O. Klinische Beiträge zur Lehre von der Lokalisation der sensiblen Rindenzentren. Prager Med Wochenschr 1914;45:548-50.

2 Garcin R, Lapresle J. Syndrome sensitif de type thalamique et à topographie chéiro-orale par lésion localisée du thalamus. Rev Neurol (Paris) 1954;90:124-9.

3 Garcin R, Lapresle J. Deuxième observation personnèle de syndrome sensitif de type thalamique et à topographie chéiroorale par lésion localisée du thalamus. Rev Neurol (Paris) 1960;103:474-81.

4 Strauss H. Uber Sensibilitätsstörungen an Hand und 'Gesicht. Geschmacksstorungen und ihre lokalisatorische Bedeutung. Monatsschr Psychiat Neurol 1925;58:265-76.

5 Araga S, Fukada M, Kagimoto H, Takahashi K. Pure sensory stroke due to pontine haemorrhage. J Neurol 1988;235:116-7.

6 Hashiguchi K, Igata A. A case of primary pontine hemorrhage with cheiro-oral syndrome. Neurol Med (Tokyo) 1976;5:79-80.

7 Ono S, Inoue $\mathrm{K}$. Cheiro-oral syndrome following midbrain haemorrhage. J Neurol 1985;232:304-6.

8 Sueda T, Minematsu K, Tagawa K, Yamaguchi T. A case of $\vec{\omega}$ pontine hemorrhage with cheiro-oral syndrome. Neurol Med (Tokyo) 1981;15:286-8.

9 Tawara S, Shirabe T, Terao A, Araki S. Unilateral MLF syndrome with palm-oral sensory disturbance-report of a case. Clin Neurol 1974;14:745-51.

10 Brodal A. Neurological Anatomy: in Relation to Clinical Medicine New York: Oxford University Press, 1981. 